\title{
PENERAPAN MEDIA VIDEO JEJAK PETUALANG TRANS 7 DALAM \\ PEMBELAJARAN ILMU PENGETAHUAN SOSIAL (IPS) UNTUK \\ MENINGKATKAN KARAKTER CINTA TANAH AIR PADA SISWA KELAS VIII G SMP NEGERI 3 LEMBANG
}

\author{
Oleh: \\ Adistya Wicaksana $H$ \\ Program Studi Pendidikan Ilmu Pengetahuan Sosial \\ Universitas Pendidikan Indonesia \\ Email: adiswicaksana@gmail.com
}

\begin{abstract}
ABSTRAK
Penelitian ini dilatarbelakangi oleh permasalahan yang ditemukan bahwa siswa kelas VIII G SMP Negeri 3 Lembang lebih menyukai kebudayaan negara lain dengan segala produk-produknya ketimbang budaya lokal. Hal ini menunjukkan menurunnya rasa cinta tanah air yang secara sengaja ataupun tidak merupakan fakta yang sangat mengkhawatirkan. Meninjau permasalahan yang akan diteliti berkaitan dengan penerapan media video Jejak Petualang Trans 7 dalam pembelajaran IPS untuk meningkatkan karakter cinta tanah air pada siswa, maka peneliti memilih metode deskriptif kualitatif dalam melakukan penelitian ini. Hasil dari penelitian ini menunjukkan bahwa penerapan media video Jejak Petualang Trans 7 dalam pembelajaran IPS mampu meningkatkan karakter cinta tanah air siswa kelas VIII G SMP Negeri 3 Lembang yang terlihat dari para siswa menjadi lebih mengenal keanekaragaman budaya dan keindahan alam Indonesia. Pengenalan siswa terhadap kebudayaan dan alam Indonesia dapat dijadikan titik awal untuk meningkatkan rasa cinta tanah air.
\end{abstract}

Kata Kunci: Karakter Cinta Tanah Air, Jejak Petualang Trans7, Pembelajaran IPS. 


\title{
APPLICATION OF MEDIA VIDEO TRACES ADVENTUROUS TRANS7 IN LEARNING SCIENCE SOCIAL (IPS) TO IMPROVE THE PATRIOTISM CHARACTER IN CLASS VIII G SMP NEGERI 3 LEMBANG
}

\author{
By: \\ Adistya Wicaksana $H$ \\ Program Studi Pendidikan Ilmu Pengetahuan Sosial \\ Universitas Pendidikan Indonesia \\ Email: adiswicaksana@gmail.com
}

\begin{abstract}
This research is motivated by the problems found that students in class VIII G SMP Negeri 3 Lembang prefers the culture of other countries with all of its products than the local culture. It showed a declining sense of patriotism that intentionally or not is a fact which is very worrying. Reviewing the issues to be examined relating to the application of video media Traces Adventurers Trans 7 in teaching social studies to improve the character of patriotism in students, the researchers chose a qualitative descriptive method in this research. The results of this study indicate that the application of video media Traces Adventurers Trans 7 in learning IPS is able to improve the character of patriotism class VIII G SMP Negeri 3 Lembang seen from the students become more familiar with cultural diversity and natural beauty of Indonesia. The introduction of students to Indonesian culture and nature can be used as a starting point to increase the love for the homeland.
\end{abstract}

Key Word: Patriotism character, Traces Adventurers Trans7, Learning IPS. 


\section{A. PENDAHULUAN}

Cinta Tanah Air dan bangsa adalah kebanggan menjadi salah satu bagian dari tanah air dan bangsanya yang berujung ingin membuat sesuatu yang mengharumkan tanah air dan bangsa. Cinta tanah air dapat diartikan juga cara berpikir, bersikap, dan berbuat yang menunjukan kesetiaan, kepedulian, dan penghargaan yang tinggi terhadap bahasa, lingkungan fisik, sosial, budaya, ekonomi, dan politik bangsa. Semangat cinta tanah air dapat disebut juga sebagai patriotisme, sedangkan rasa cinta terhadap bangsa dapat disebut juga sebagai nasionalisme. Mengembangkan rasa cinta kepada tanah air dan bangsa termasuk butir-butir Pancasila yaitu pada sila ke tiga yaitu persatuan Indonesia. Sehingga sebagai warga Indonesia harus mengembangkan rasa cinta kepada tanah air dan bangsa sebagai pengamalan terhadap Pancasila (Jamli : 2005, hlm 1).

Indonesia dilahirkan oleh generasi yang mempunyai idealisme cinta tanah air dan bangsayang sangat tinggi, kalau tidak mempunyai rasa kesadaran terhadap tanah dan air nya, mungkin sampai saat ini kita masih di dalam penjajahan bangsa asing. Dengan mempunyai rasa cinta tanah air yang tinggi maka setiap perjuangan yang dilakukan dapat menghasilkan hasil yang maksimal melawan semua kekuatan penjajahan yang dilakukan oleh bangsa asing. Hasil kemerdekaan yang sekarang kita rasakan hari ini merupakan hasil jerih payah perjuangan para pahlawan pejuang, maka dengan itu kita harus sangat berterima kasih banyak kepada jasa para pejuang kemerdekaan atas usahanya yang telah merintis dan membangun Negara Kesatuan Republik Indonesia samapai sekarang. Adapun rasa hormat kita terhadap jasa para pejuang adalah dengan menjadi warga negara Indonesia yang baik dan mempunyai rasa cinta tanah air yang kuat dan berkarakter agar dapat melanjutkan perjuangan dalam menjaga keutuhan Negara Kesatuan Republik Indonesia (Mulyati : 2007, hlm. 12).

Semakin berkembangnya zaman, rasa cinta kepada tanah air dan bangsa semakin luntur. Generasi muda sebagai generasi penerus bangsa malah berkiblat pada budaya lain yang tidak mencerminkan jati diri bangsa. Hal ini dibuktikan dari berbagai sikap dalam memaknai berbagai hal penting bagi Negara Indonesia. Contoh sederhana yang menggambarkan betapa kecilnya rasa nasionalisme dari masyarakat Indonesia, diantaranya (Solihin : 2014, hlm. 2):

1. Pada saat upacara bendera, masih banyak rakyat yang tidak memaknai arti dari upacara tersebut. Upacara merupakan wadah untuk menghormati dan menghargai para pahlawan yang telah berjuang keras untuk mengambil kemerdekaan dari tangan para penjajah. Para pemuda 
seakan sibuk dengan pikirannya sendiri, tanpa mengikuti upacara dengan khidmad.

2. Pada peringatan hari-hari besar nasional, seperti Sumpah Pemuda atau HUT RI, hannya dimaknai sebagai serermonial dan hiburan saja tanpa menumbuhkan rasa nasionalisme dan patriotisme dalam benak mereka.

3. Lebih tertariknya masyarakat terhadap produk impor dibandingkan dengan produk buatan dalam negeri, lebih banyak mencampurkan bahasa asing dengan bahasa Indonesia untuk meningkatkan gengsi, dan lain-lain.

4. Kurangnya kesadaran masyarakat "hanya" untuk memasang bendera di depan rumah, kantor atau pertokoan. Dan bagi yang tidak mengibarkannya mereka punya berbagai macam alasan misal benderanya sudah sobek atau tidak punya tiang bendera, malas, cuaca buruk, dan lain-lain. Mereka mampu membeli sepeda motor baru, baju baru tiap tahun yang harganya ratusan bahkan jutaan tetapi untuk bendera merah putih yang harganya tidak sampai ratusan saja mereka tidak sanggup.

5. Semua identitas bangsa Indonesia baik itu bendera merah putih, lagu kebangsaan Indonesia Raya dan lain sebagainya hanyalah merupakan simbol tanpa mengetahui makna dari identitas bangsa tersebut yang sesungguhnya.

Hal tersebut di atas merupakan cerminan betapa lunturnya rasa cinta tanah air yang dimiliki bangsa ini. Dengan memudarnya rasa cinta tanah air dapat mengancam dan menghancurkan bangsa Indonesia. Hal itu terjadi karena ketahanan nasional akan menjadi lemah dan dapat dengan mudah ditembus oleh pihak luar. Banyak sekali kebudayaan dan paham barat yang masuk ke dalam bangsa Indonesia. Banyak budaya dan paham barat yang berpengaruh negatif dapat dengan mudah masuk dan diterima oleh bangsa Indonesia. Dengan terjadinya hal itu, maka akan terjadi akulturasi, bahkan menghilangnya kebudayaan dan kepribadian bangsa yang seharusnya menjadi jati diri bangsa (Solihin : 2014, hlm. 2).

Melihat fenomena zaman sekarang yang kebanyakan orang Indonesia khusunya para siswa sekolah yang lebih menyukai kebudayaan negara lain dengan segala produk-produknya adalah salah satu ciri menurunnya rasa cinta tanah air yang secara sengaja ataupun tidak merupakan ironi yang sangat mengkhawatirkan, padahal potensi kebudayaan negara sendiri lebih menarik dan beragam, diantaranya adalah kekayaan alam dan kebudayaan lokal salah satu contoh misalnya kita mengenal pantai Hawai yang terletak di negeri orang, sedangkan pantai di Indonesia yang terletak di Raja Ampat tidak kalah indahnya dengan pantai di luar sana (Mulyati, 2002, hlm. 4).

Rasa cinta tanah air siswa SMP Negeri 3 Lembang belum dapat dikatakan sesuai dengan harapan. Lunturnya rasa cinta terhadap tanah air dari siswa SMP Negeri 3 Lembang dapat dilihat dalam contoh sederhana sebagai berikut:

1. Upacara bendera yang dilakukan setiap hari senin sebagai wujud penghormatan kepada sang saka merah putih dan jasa para pahlawan, 
peseta upacara atau para murid malah berbicara sendiri, bahkan guru sebagai teladan ikut bercakap-cakap. Upacara bendera dianggap tidak penting dan membuat lelah.

2. Para siswa belum mampu menggunakan bahasa Indonesia dengan baik dan benar di dalam maupun di luar kelas. Bahkan sebagian siswa terlihat merasa bangga menggunakan bahasa Inggris dalam pergaulan seharihari.

3. Kebanyakan siswa menghindari kegiatan ekstrakulikuler yang sifatnya kegiatan berorganisasi, sehingga kerjasama antar sesama siswa kurang terbangun di sekolah ini.

4. Masih banyak siswa yang tidak hafal bahkan tidak tahu lagu-lagu daerah dan lagu nasional Indonesia.

5. Terdapat siswa yang sering melakukan perbuatan yang melanggar norma atau peraturan, khususnya peraturan di sekolah, misalnya ada siswa yang merokok di lingkungan sekolah walaupun sembunyi-sembunyi.

Penanaman rasa cinta tanah air terhadap siswa sekolah khususnya siswa SMP bisa dengan cara mengikuti pembelajaran IPS di sekolah masing-masing (Gunawan, 2012, hlm. 71). Adapun cara memberikan materi pembelajaran IPS terhadap siswa bisa dengan banyak cara, salah satunya dengan menggunakan media tayangan televisi yang mempunyai visi misi yang sama untuk meningkatkan karakter cinta tanah air semua orang yang menontonnya. Saat ini banyak tayangan yang dapat menumbuhkan rasa kecintaan kita terhadap tanah air Indonesia salah satunya adalah acara Jejak Petualang yang disiarkan melalui stasiun televisi Trans 7. Jejak Petualang merupakan acara yang memberikan informasi mengenai kebudayaan, kekayaan alam, kekhasan suatu daerah yang ada diberbagai tempat di Indonesia. Melalui acara ini yang di tayangkan terhadap siswa dengan materi yang disesuaikan dengan mata pelajaran IPS di sekolah SMP, diharapkan siswa mampu memperoleh berbagai informasi mengenai keragaman yang ada di Indonesia dan dengan memperoleh informasi tersebut maka rasa cinta terhadap tanah airakan timbul dalam diri siswa.

Berdasarkan permasalahan yang telah dipaparkan sebelumnya, maka rumusan dalam penelitian ini yaitu: Pertama, Bagaimana proses pembelajaran IPS yang dilaksanakan di SMP Negeri 3 Lembang? Kedua, Bagaimana penerapan karakter cinta tanah air siswa di kelas VIII G SMP Negeri 3 Lembang? Ketiga, Apakah tayangan jejak petualang dapat dijadikan sebagai media dalam pembelajaran IPS dalam upaya meningkatkan karakter cinta tanah air siswa di kelas VIII G SMP Negeri 3 Lembang?

\section{B. METODE PENELITIAN}

Metode penelitian yang digunakan dalam penelitian ini adalah metode deskriptif kualitatif. Pemilihan metode deskriptif kualitatif digunakan untuk dapat mengungkapkan tentang gambaran proses penerapan karakter cinta tanah air siswa 
melalui tayangan jejak petualang Trans7 pada siswa kelas VIII G SMP Negeri 3 Lembang.

Teknik pengumpulan data yang digunakan penulis dalam penelitian ini adalah observasi, wawancara, studi literatur, dokumentasi dan catatan lapangan. Seluruh data yang telah diperoleh melalui observasi, wawancara, dan catatan lapangan tersebut, dikumpulkan dan disusun secara sistematis untuk kemudian diolah dan dianalis untuk memecahkan masalah yang diteliti, serta dapat diketahui hubungan dalam setiap masalah.

Seluruh data yang telah diperoleh melalui observasi, wawancara, dan catatan lapangan tersebut, dikumpulkan dan disusun secara sistematis untuk kemudian diolah dan dianalis untuk memecahkan masalah yang diteliti, serta dapat diketahui hubungan dalam setiap masalah. Adapun data-data tersebut diolah dengan cara sebagai berikut:

1. Data hasil wawancara, observasi dan catatan lapangan dideskripsikan.

2. Dilakukan pemilihan data dan disesuaikan dengan pertanyaan penelitian.

3. Data hasil wawancara, observasi, catatan lapangan dan studi literatur disusun sesuai pertanyaan penelitian.

4. Laporan disusun sesuai keseluruhan data yang diperoleh sampai batas waktu berakhir. Format laporan disesuaikan dengan pedoman wawancara.

\section{HASIL PENELITIAN DAN PEMBAHASAN}

Upaya meningkatkan karakter cinta tanah air siswa di kelas VIII G SMP Negeri 3 Lembang dilakukan dengan beberapa cara, yaitu:

1. Melaksanakan upacara bendera setiap hari senin.

Upacara bendera hari senin merupakan bukti bahwa negara Indonesia selalu menghargai jasa-jasa pahlawan yang sudah memperjuangkan kemerdekaan. Siswa SMP Negeri 3 Lembang rutin melaksanakan upacara bendera setiap hari senin sebagaimana yang dilakukan di sekolah-sekolah lainnya. Upacara bendera yang dilaksanakan sebagai kegiatan rutin setiap hari Senin di sekolah memiliki nilai filosofis yang mendalam yang cukup dipahami banyak siswa di SMP Negeri 3 Lembang.

2. Melatih siswa untuk aktif dalam berorganisasi.

Kegiatan organisasi merupakan salah satu kegiatan ekstrakurikuler yang dapat diikuti siswa melalui pendidikan di sekolah. Di sekolah, kegiatan berorganisasi yang dapat diikuti oleh siswa salah satunya adalah Organisasi Siswa Intra Sekolah (OSIS). Kegiatan OSIS tidak melulu menghabiskan waktu siswa. Intensitas kegiatan OSIS hanya terjadi pada saat pelaksanaan MOS, Pensi dan LDK saja. Berbeda dengan keberadaan ekskul lain yang tiap minggunya memiliki jadwal kegiatan dan latihan secara rutin. Selain hal tersebut, pemaknaan siswa mengikuti OSIS tidak lepas pula pada sebuah true culture di mana siswa ingin 
menambah teman, memperluas pergaulan, aktif berkegiatan, termotivasi oleh pacar dan menyalurkan gairah masa mudanya.

3. Mengajarkan lagu-lagu daerah dan lagu wajib nasional kepada siswa.

Kegiatan menyanyikan lagu-lagu wajib nasional dan daerah sebelum pelajaran dimulai dan ketika jam sekolah berakhir sudah mulai aktif dilakukan di SMP Negeri 3 Lembang. Tujuannya, selain untuk menyegarkan pikiran siswa dan membuat mereka tetap bersemangat, juga untuk menumbuhkan rasa kesadaran berbangsa dan bertanah air.

4. Penggunaan Bahasa Indonesia dalam aktivitas sehari-hari.

Pentingnya berbahasa Indonesia yang baik dan benar didasarkan pada alasan bahwa bahasa Indonesia merupakan bahasa nasional dan bahasa persatuan yang telah disepakati sejak Sumpah Pemuda pada 28 Oktober 1928. Penggunaan bahasa nasional dalam kehidupan sehari-hari sudah dapat dikatakan salah satu upaya mewujudkan cinta tanah air karena secara langsung atau tidak kita telah mengajarkan kepada siswa untuk melestarikan bahasa Indonesia. Penggunaan bahasa Indonesia oleh kebanyakan siswa kelas VIII G SMP Negeri 3 Lembang ternyata pada saat jam belajar saja. Di luar jam belajar kebanyakan siswa memakai bahasa daerah.

5. Memberikan Pendidikan moral.

Pendidikan moral sangatlah perlu bagi manusia, karena melalui pendidikan perkembangan moral diharapkan mampu berjalan dengan baik, serasi dan sesuai dengan norma demi harkat dan martabat manusia itu sendiri. Di SMP Negeri 3 Lembang perkembangan pendidikan moral tak pernah beranjak dari nilai-nilai luhur yang ada dalam tatanan moral bangsa Indonesia yang termaktub jelas dalam Pancasila sebagai dasar negara. Dengan pemberian pendidikan moral tersebut diharapkan dapat membentuk siswa yang berkualitas sehingga bisa membangun bangsa.

Rasa cinta tanah air atau nasionalisme adalah rasa kebanggaan, rasa memiliki, rasa menghargai, rasa menghormati dan loyalitas yang dimiliki oleh setiap individu pada negara tempat ia tinggal yang tercermin dari perilaku membela tanah airnya, menjaga dan melindungi tanah airnya, rela berkorban demi kepentingan bangsa dan negaranya, mencintai adat atau budaya yang ada dinegaranya dengan melestarikannya dan melestarikan alam dan lingkungan.

Warga negara Indonesia memiliki kewajiban untuk cinta terhadap tanah air Indonesia. Cinta tanah air bukan untuk dihafal, tetapi harus diwujudkan dalam kehidupan sehari-hari melalui berbagai kegiatan sesuai dengan bidang dan keahlian masing-masing. Cinta tanah air diartikan suatu sikap yang mementingkan kepentingan bangsa dan negara serta rela berkorban demi kejayaan bangsa dan negara.

Individu yang memiliki rasa cinta pada tanah airnya akan berusaha dengan segala daya upaya yang dimilikinya untuk melindungi, menjaga kedaulatan, kehormatan dan segala apa yang dimiliki oleh negaranya. Rasa cinta tanah air inilah yang mendorong perilaku individu untuk membangun negaranya dengan penuh dedikasi. Oleh karena itu, rasa cinta tanah air perlu ditumbuhkembangkan 
dalam jiwa setiap individu yang menjadi warga dari sebuah negara atau bangsa agar tujuan hidup bersama dapat tercapai.

Salah satu cara untuk menumbuhkembangkan rasa cinta tanah air adalah dengan menumbuhkan rasa bangga terhadap tanah airnya melalui proses pendidikan. Rasa bangga terhadap tanah air dapat ditumbuhkan dengan memberikan pengetahuan dan dengan membagi dan berbagi nilai-nilai budaya yang kita miliki bersama. Oleh karena itu, pendidikan berbasis nilai-nilai budaya dapat dijadikan sebagai sebuah alternatif untuk menumbuhkembangkan rasa bangga yang akan melandasi munculnya rasa cinta tanah air.

Pendidikan yang ditawarkan sekolah seharusnya mampu menjawab permasalahan yang berkaitan dengan rasa cinta tanah air para siswa dengan mereposisi ranah pendidikan nasionalisme. Rasa cinta tanah air seringkali disangka akan muncul secara otomatis ketika siswa mampu menghafal serta mengulas pelajaran-pelajaran sejarah dan mengenal budaya bangsa Indonesia. Metode pembelajaran yang seperti ini hanya berada di ranah kognitif yang menempatkan karakter cinta tanah air sebagai pengetahuan yang harus dihafal dan dimengerti.

Sudah sangat umum bahwa guru mengajarkan pengetahuan tentang nasionalisme dengan menjelaskan kepada siswa tentang sejarah kebangsaan. Selanjutnya, siswa diminta untuk menghafal ataupun memahami topik-topik pelajaran yang sedang dibahas. Ukuran kesusksesan siswa adalah nilai yang baik di dalam rapor berdasarkan kemampuan mereka untuk menceritakan kembali ingatan mereka tentang cerita kebangsaan tersebut.

Karakter cinta tanah air haruslah lebih dari sekedar pengetahuan. Karakter cinta tanah air merupakan sebuah kesadaran yang terbangun karena akal dan rasa berpadu. Pendidikan karakter cinta tanah air harus bertumpu pada ranah afektif yang terus menerus dipupuk pada siswa sehingga mereka mencapai tahap internalisasi yang membuat mereka mampu menjadi nasionalis-nasionalis yang mampu membawa Indonesia ke dalam percaturan dunia internasional.

Berkaitan dengan menanamkan karakter cinta tanah air, tayangan Jejak Petualang dirasa mampu menjadi media untuk menumbuhkan dan meningkatkan karakter cinta tanah air pada siswa kelas VIII G SMP Negeri 3 Lembang. Berdasarkan observasi yang peneliti lakukan, terdapat gambaran karakter cinta tanah air dalam tayangan "Jejak Petualang" yang disiarkan Trans 7 yang dapat dilihat pada adegan dan dialog sebagai berikut:

1. Menggunakan bahasa Indonesia yang baik dan benar.

Berbahasa Indonesia dengan baik dan benar dapat diartikan sebagai pemakaian ragam bahasa yang serasi dengan sasarannya. Selain itu, pemakaian bahasa Indonesia yang baik dan benar harus mengikuti kaidah bahasa yang betul. Ungkapan bahasa Indonesia yang baik dan benar mengacu pada ragam bahasa baku. Berbahasa Indonesia dengan baik dan benar mempunyai beberapa konsekuensi logis terkait dengan pemakaiannya sesuai dengan situasi dan kondisi. Pada kondisi tertentu misalnya pada situasi formal penggunaan bahasa Indonesia yang baik dan benar menjadi prioritas utama. Kendala dalam pemakaian bahasa Indonesia yang baku antara lain disebabkan adanya gejala bahasa seperti 
interferensi, integrasi, campur kode, alih kode dan bahasa gaul yang tanpa disadari sering digunakan dalam komunikasi resmi. Penggunaan bahasa Indonesia yang baik dan benar terdapat di dalam beberapa adegan dan dialog pada tayangan Jejak Petualang.

2. Menyukai budaya nusantara.

Bangsa Indonesia memiliki budaya yang sangat beragam, akan tetapi kekayaan budaya yang dimiliki secara perlahan menghilang. Masyarakat khususnya generasi muda tidak lagi mengenal dan melestarikannya. Tayangan Jejak Petualang menampilkan berbagai kesenian yang merupakan salah satu budaya warisan nenek moyang bangsa Indonesia yang masih disukai pada masa itu, misalnya tari-tarian daerah, upacaraupacara adat dan lain sebagainya.

3. Menyukai buatan Indonesia.

Mencintai produk buatan Indonesia memang harus sangat ditunjang oleh pemerintah agar tidak hanya menjadi semboyan saja, apalagi produkproduk dari luar negeri sudah membanjiri pasar Indonesia, baik yang murah dan tak berkualitas maupun yang mahal. Tayangan Jejak Peteualang banyak menampilkan tayangan yang didalamnya mengandung pesan untuk mencintai buatan Indonesia.

Siswa kelas VIII G SMP Negeri 3 Lembang dapat mengetahui salah satu aspek karakter cinta tanah air yaitu menyukai budaya Indonesia. Pengetahuan mengenai adat istiadat lokal maupun nasional dan pemahaman mengenai nilainilai bersama sebagai hasil dari proses pendidikan berbasis nilai-nilai budaya lokal dan nasional akan membentuk manusia Indonesia yang bangga terhadap tanah airnya. Rasa kebanggaan ini akan menimbulkan rasa cinta pada tanah airnya yang kemudian akan mengejawantah dalam perilaku melindungi, menjaga kedaulatan, kehormatan dan segala apa yang dimiliki oleh negaranya.

Pelaksanaan pembelajaran IPS yang sekaligus menanamkan karakter cinta tanah air melalui tayangan "Jejak Petualang" terdiri dari kegiatan pendahuluan, kegiatan inti dan kegiatan penutup. Dengan menggunakan media pembelajaran berbasis multimedia dapat memadukan media-media dalam proses pembelajaran, maka proses pembelajaran akan berkembang dengan baik, sehingga membantu guru menciptakan pola penyajian yang interaktif. Di samping itu, pembelajaran menggunakan media tayangan Jejak Petualang Trans 7 di SMP Negeri 3 Lembang dikembangkan pula model pembelajaran CTL. Pengembangan model pembelajaran CTL yang dipadukan dengan penggunaan media visual merupakan salah satu model pembelajaran yang diharapkan dapat meningkatkan motivasi dan aktivitas peserta didik dan akhirnya dapat meningkatkan prestasi belajar peserta didik (Sapriya, 2004, hlm.28). Sehingga dapat memudahkan pendidik untuk mempraktikkan model pembelajaran yang inovatif yang dapat meningkatkan prestasi belajar peserta didik.

Program Jejak Petualang ini memiliki keunggulan, yaitu tidak hanya menyajikan keindahan alam dan keragaman budaya namun juga menyajikan permasalahan yang sebenarnya dihadapi Indonesia. Selain itu, program 
dokumenter ini tidak hanya sekadar mendokumentasikan perjalanan (travelling), namun juga melihat Indonesia dari sudut pandang yang berbeda dan menampilkan tokoh-tokoh inspiratif, yaitu orang-orang yang berjuang demi perubahan. Tayangan Jejak Petualang sangat cocok dijadikan media penanaman cinta tanah air kepada siswa, karena tayangan ini menyajikan keragaman budaya bangsa Indonesia dan keindahan alamnya. Jejak Petualang menyajikan suatu kegiatan petualang yang menjelajahi alam Indonesia serta mengeksplor apa dan di mana tempat peliputannya yang dikemas secara dokumenter sehingga menjadi menarik untuk ditonton.

Pembelajaran dengan tayangan "Jejak Petualang" akan lebih berhasil daripada menggunakan media jenis audio saja atau visual saja. Hal ini karena tayangan "Jejak Petualang" yang disiarkan Trans 7 menggunakan suara dan gambar sehingga lebih menarik, dan efek yang dihasilkan akan lebih dalam karena informasi masuk melalui dua indera pada manusia yakni mata dan telinga. Dengan media ini pula, siswa akan merasa bahwa mereka seolah-olah terlibat di dalam kegiatan itu sendiri, sehingga diharapkan penggunaan media ini akan dapat meningkatkan pemahaman siswa terhadap materi pelajaran (Sudjana dan Ahmad, 2005, hlm. 38).

Selama ini yang menjadi faktor penyebab ketertarikan siswa pada mata pelajaran IPS di SMP Negeri 3 Lembang adalah faktor guru atau pengajar, bahan pelajaran, media pembelajaran, serta fasilitas pendidikan yang menunjang. Dari segi media pembelajaran, ketertarikan siswa juga tergolong cukup tinggi.

Para siswa sangat antusias terhadap model pembelajaran dengan menggunakan media tayangan Jejak Petualang. Dengan menggunakan media tayangan Jejak Petualang menimbulkan minat siswa dalam belajar IPS. Oleh karena itu, dapat dijelaskan bahwa minat dibentuk karena ketertarikan seseorang peserta didik terhadap suasana pembelajaran, maka dari itu pemilihan strategi dan didukung oleh media pembelajaran yang tepat akan meningkatkan minat belajar peserta didik (Suwarno dan Amir, 2009, hlm. 4). Minat belajar merupakan ketertarikan siswa dalam proses belajar sehingga digunakan sebagai alasan untuk memotivasi siswa agar aktivitas belajarnya mencapai maksimal.

Gambaran karakter cinta tanah air yang terkandung dalam tayangan Jejak Petualang yang disiarkan Tran 7 cukup diketahui oleh para siswa kelas VIII G SMP Negeri 3 Lembang, terutama terkait dengan isi tayangan Jejak Petualang yang mengeksplor keragaman budaya dan keindahan alam di Indonesia. Dari tayangan Jejak Petualang, siswa kelas VIII G SMP Negeri 3 Lembang banyak mengenal budaya Indonesia.

Siswa kelas VIII G SMP Negeri 3 Lembang dapat mengetahui salah satu aspek karakter cinta tanah air yaitu menyukai budaya Indonesia. Pengetahuan mengenai adat istiadat lokal maupun nasional dan pemahaman mengenai nilainilai bersama sebagai hasil dari proses pendidikan berbasis nilai-nilai budaya lokal dan nasional akan membentuk manusia Indonesia yang bangga terhadap tanah airnya. Rasa kebanggaan ini akan menimbulkan rasa cinta pada tanah airnya yang kemudian akan mengejawantah dalam perilaku melindungi, menjaga kedaulatan, kehormatan dan segala apa yang dimiliki oleh negaranya. 
Berdasarkan hasil observasi terhadap pembelajaran IPS yang menggunakan media video Jejak Petualang terlihat bahwa para siswa menjadi lebih mengenal keanekaragaman budaya dan keindahan alam Indonesia dan juga sejarah perjuangan pahlawan bangsa. Pengenalan siswa terhadap kebudayaan dan alam Indonesia serta sejarah perjuangan pahlawan bangsa dapat dijadikan titik awal untuk meningkatkan rasa cinta tanah air.

\section{KESIMPULAN}

Pertama, penerapan nilai-nilai cinta tanah air kepada siswa di Kelas VIII G SMP Negeri 3 Lembang dilakukan dengan cara: Melaksanakan upacara bendera setiap hari senin, artinya upacara bendera merupakan salah satu bentuk penghormatan siswa kepada jasa para pahlawan. Melatih siswa untuk aktif dalam berorganisasi, artinya siswa dilatih untuk melakukan kerja sama dalam bentuk kegiatan organisasi. Mengajarkan lagu-lagu daerah dan lagu wajib nasional kepada siswa, yang bertujuan membuat siswa memiliki karakter yang baik melalui kegiatan ini. Penggunaan Bahasa Indonesia dalam aktivitas sehari-hari, artinya siswa harus memiliki etika berbahasa dalam kehidupan berbangsa dan bernegara. Memberikan pendidikan moral yang bertujuan untuk membentuk siswa agar menjadi orang bersusila yang cakap, berguna bagi agama, nusa dan bangsa di masa yang akan datang.

Kedua, ada tiga tahap proses pembelajaran IPS yang dilaksanakan guru di kelas VIII G SMP Negeri 3 Lembang yaitu: Kegiatan pendahuluan (awal) yang bertujuan menciptakan suasana kelas yang kondusif sehingga siswa siap mengikuti proses belajar mengajar. Kemudian kegiatan inti pembelajaran yaitu kegiatan dalam rangka pelaksanaan pembelajaran terpadu yang menekankan pada proses pembentukan pengalaman (learning experience) bagi peserta didik yang bersifat situasional artinya pembelajaran terpadu dapat disesuaikan dengan situasi dan kondisi tempat proses pembelajaran berlangsung. Terakhir kegiatan penutup/tindak lanjut yang bertujuan untuk menenangkan dan melakukan refleksi dalam rangka evaluasi pembelajaran. Berdasarkan hasil observasi, tampak bahwa kegiatan pembelajaran IPS yang dilakukan di kelas VIII G SMP Negeri 3 Lembang telah berjalan dengan baik.

Ketiga, karakter cinta tanah air siswa kelas VIII G SMP Negeri 3 Lembang mengalami perkembangan setelah menyaksikan tayangan Jejak Petualang yang dijadikan media pembelajaran IPS. Dengan menggunakan media tayangan Jejak Petualang menimbulkan minat siswa dalam belajar IPS serta menumbuhkan kesukaaan siswa terhadap keragaman budaya dan keindahan alam Indonesia. Hal ini menunjukkan bahwa pembelajaran yang menggunakan media video Jejak Petualang membuat para siswa menjadi lebih mengenal keanekaragaman budaya dan keindahan alam Indonesia. Pengenalan siswa terhadap kebudayaan dan alam Indonesia dapat dijadikan titik awal untuk meningkatkan rasa cinta tanah air. 


\section{DAFTAR PUSTAKA}

Anggraeni, Eny. (2009). Pendidikan Karakter untuk Sekolah Menengah Pertama. Jakarta: Bhuana Ilmu Populer.

Chalim, Syamsuddin. Integrasi Wawasan Kebangsaan ke dalam Perangkat Pembelajaran IPS Kelas VIII di SMP PGRI 9 Sidoarjo. Jurnal Ilmu Pengetahuan Sosial. Surabaya: UNESA.

Daryanto. (2011). Media Pembelajaran. Bandung: Sarana Tutorial Nurani.

Gunawan, H. (2012). Pendidikan Karakter: Konsep dan Implementasi. Bandung: Alfabeta.

Mulyati, Susi Sri. (2002). Cinta Tanah Air. Bandung: Mizan Pustaka.

Narwati, Sri. (2011). Pendidikan Karakter. Yogyakarta: Familia.

Rudi, S. dan Cepi, R. (2008). Media Pembelajaran. Bandung: Kurtekpen FIP UPI.

Sapriya. (2014). Pendidikan IPS: Konsep Dan Pembelajaran. Bandung: Remaja Rosdakarya.

Sapriya, Nurdin, S. \& Susilawati. (2007). Konsep Dasar IPS. Bandung: Universitas Pendidikan Indonesia.

Sudjana, N dan Ahmad R. (2005) Media Pengajaran. Bandung : Sinar Baru.

Sukaryono. 2002. Pendidikan sebagai Prioritas untuk Mengatasi Krisis Bangsa. Jurnal Pendidikan Dasar dan Menengah. Surabaya: Dinas Pendidikan dan Kebudayaan Provinsi Jawa Timur.

Suwarno WA, Hadiyah, dan Amir. (2009). "Penggunaan Media Audio Visual untuk Meningkatkan Hasil Belajar PKN”. Jurnal Penelitian.

Zahera. 2000. Cara Guru Memotivasi dan Pengaruhnya Terhadap Aktivitas Siswa dalam Proses Pembelajaran. Jurnal Ilmu Pendidikan. LPTK (Lembaga Pendidikan dan Tenaga Kependidikan) dan ISPI (Ikatan Sarjana Pendidikan Indonesia). Universitas Negeri Malang. Jilid 5. Pebruari 2000. 